\title{
Photo-promoting Fabrication of Silver Nanoparticles in the Presence of Anthracenyl-Focal PAMAM Dendrons
}

\author{
Chisato Hirano, ${ }^{1}$ Toyoko Imae, $, 2, \dagger$ Yasushi Yanagimoto, ${ }^{3}$ and Yutaka TAKaguCHI ${ }^{3}$ \\ ${ }^{1}$ Graduate School of Science, Nagoya University, Furo-cho, Chikusa-ku, Nagoya 464-8602, Japan \\ ${ }^{2}$ Research Center for Materials Science, Nagoya University, Furo-cho, Chikusa-ku, Nagoya 464-8602, Japan \\ ${ }^{3}$ Graduate School of Natural Science and Technology, Okayama University, \\ 3-1-1 Tsushimanaka, Okayama 700-8530, Japan
}

(Received June 7, 2005; Accepted August 28, 2005; Published January 15, 2006)

\begin{abstract}
Silver nanoparticles protected by first to third generation poly(amido amine) dendrons with an anthracenyl-focal point were fabricated by photo-promotion of silver ions in aqueous dendron solutions. The reaction solutions colored from light to deep brown and displayed a broad plasmon band at $450 \mathrm{~nm}$, indicating the formation of silver nanoparticles. The formation of particles progressed with time, although it slowed down at the light-shielding (dark) condition. The light-promoted electron transfer from amine groups of dendron to silver ions through anthracenyl moiety might concern to the formation of silver nanoparticles. According to the images of transmission electron microscopy, the shape of nanoparticles was not only spherical ( $15-20 \mathrm{~nm}$ in size) but also polygonal (20-35 $\mathrm{nm}$ in size). It was confirmed from the crystallographic analysis of electron diffraction patterns that the polygon was a hexagonalclose-packing (hcp) single crystal, whereas the crystal structure of spherical nanoparticles was face-centered-cubic (fcc). The reaction was fastest when the second generation dendron was used, indicating the competition of increasing number of amine groups and reducing efficiency of photo-promoted electron transfer with generation.
\end{abstract}

[DOI 10.1295/polymj.38.44]

KEY WORDS Poly(amido amine) Dendron / Anthracene / Anthracenyl-focal Poly(amido amine) Dendron / Silver Nanoparticle / Nanoparticle / Photo-induction / Photo-fabrication / Transmission Electron Microscopy / Electron Diffraction / Hexagonal-close-packing / Face-centered-cubic /

Dendrimers are synthesized stepwise through branching points and spacers, resulting in the spherical shape. From their structural characteristics like a lot of terminal groups and internal voids, the unique applications of dendrimers are prospective. Especially, poly(amido amine) (PAMAM) dendrimers with simple hydrophilic terminal groups are water-soluble and nontoxic, indicating bio-compatible. Utilizing the PAMAM dendrimers as a protector, metal and metalderivative nanoparticles with small size and narrow size distribution were synthesized..$^{1-12}$ Then the protection by PAMAM dendrimers may develop the advanced application of nanoparticles as medical materials like therapeutic reagents besides industrial materials.

Water-dispersible gold and silver nanoparticles with small sizes (less than $10 \mathrm{~nm}$ ) were synthesized by the reduction of metal ions in the presence of PAMAM dendrimers. ${ }^{3-9}$ While in almost of investigations, metal nanoparticles were reduced with the aid of reducer, gold and silver nanoparticles were prepared by reducing the metal salt in PAMAM dendrimer solutions under UV, X-ray, or laser irradiation or heating. ${ }^{3,4,6-8}$ Particle sizes and their dispersion in water depended on the generation of dendrimers and the mixing ratio of metal ion and dendrimer.
In the present work, the fabrication of silver nanoparticles without coexistence of common reducer has been reported. The silver nanoparticles were prepared with a photochemical method: Silver ions were reduced by means of light irradiation. Then it was expected that the additive, PAMAM dendron with an anthracenyl-focal point, might act as a stabilizer and a reducer. Resultant silver nanoparticles were characterized by UV-vis absorption spectroscopy and transmission electron microscopy (TEM). Then the influence of light condition and dendron generation on fabrication of silver nanoparticles was compared and discussed.

\section{EXPERIMENTAL SECTION}

Synthesis of anthracenyl-focal PAMAM dendrons with amine terminal groups ( $\mathrm{An}\left(\mathrm{G} n-\mathrm{NH}_{2}\right), n=1,2,3$ ) was carried out according to the previous report. ${ }^{13,14}$ The 4th generation PAMAM dendrimer with amine terminal groups and $\mathrm{AgNO}_{3}$ were purchased from Aldrich Chemical Co. and used as received without further purification. Ultrapure water (Milli-Q, Millipore Co., $18.3 \mathrm{M} \Omega$ ) was used throughout the experiment.

${ }^{\dagger}$ To whom correspondence should be addressed (Tel: +81-52-789-5911, Fax: +81-52-789-5912, E-mail: imae@ nano.chem.nagoya-u.ac.jp). 
$\mathrm{An}\left(\mathrm{G} n-\mathrm{NH}_{2}\right)$-protected silver $\left(\mathrm{Ag}-\mathrm{An}\left(\mathrm{G} n-\mathrm{NH}_{2}\right)\right)$ nanoparticles were synthesized by adding solid An$\left(\mathrm{G} n-\mathrm{NH}_{2}\right)$ to an aqueous solution of $\mathrm{AgNO}_{3}(1 \mathrm{mM})$ and leaving at rest in the room (under natural room lighting), in the dark place (under light-shielding) or in the vicinity of fluorescent lamp (under fluorescent lamp). Then number ratio $\left(\left[\mathrm{Ag}^{+}\right]:\left[\mathrm{NH}_{2}\right]\right)$ of metal ion to terminal amine group in $\mathrm{An}\left(\mathrm{G} n-\mathrm{NH}_{2}\right)$ was $1: 2,1: 10$ or $1: 20$.

UV-vis absorption spectra of nanoparticle suspensions in water were measured in a $1 \mathrm{~mm}$ quartz cell on a Shimadzu UV-2200 spectrometer. TEM observation was carried out on a Hitachi H-7000 microscope operated at $100 \mathrm{kV}$. Liquid film of the suspension was dried on a copper grid coated with thin amorphous Formver carbon film.

\section{RESULTS AND DISCUSSION}

Photo-fabrication and Characterization of $\mathrm{Ag}-\mathrm{An}$ (G1-NH2) Nanoparticles (Mixing Ratio 1:2)

Figure 1a shows UV-vis absorption spectra of an aqueous suspension of $\mathrm{Ag}-\mathrm{An}\left(\mathrm{G} 1-\mathrm{NH}_{2}\right)$ nanoparticles (mixing ratio 1:2) just after mixing and after $10 \mathrm{~d}$ under natural room light. Just after mixing, the spectrum displayed four absorption bands at 325, 345, 369 and $390 \mathrm{~nm}$. These bands are mainly attributed to anthracenyl moiety in $\mathrm{An}\left(\mathrm{G} 1-\mathrm{NH}_{2}\right)$, since it is common knowledge that anthracene molecule has intrinsic absorption bands in this region. After $10 \mathrm{~d}$, in addition to anthracenyl bands, a broad band centered at $450 \mathrm{~nm}$ appeared. The new band is assigned to the plasmon band of the silver nanoparticles. ${ }^{5}$

Formation of $\mathrm{Ag}-\mathrm{An}\left(\mathrm{G} 1-\mathrm{NH}_{2}\right)$ nanoparticles (mixing ratio 1:2) in water at the room light and lightshielding conditions was tracked by the color of suspensions, and the photographs of suspensions are shown in Figure 1b. Under the room light, the color varied from light to dark brown faster than that at the light-shielding condition. From this result, it is obvious that the formation of the silver nanoparticles was promoted by the light, although their slow formation was possible even in the dark condition.

Figure 2 shows TEM images of $\mathrm{Ag}-\mathrm{An}\left(\mathrm{G} 1-\mathrm{NH}_{2}\right)$ nanoparticles (mixing ratio 1:2) at one month incubation. At the room light condition, some nanoparticles were spherical (size: 15-20 nm) and some were polygonal (size: $20-35 \mathrm{~nm}$ ). At the light-shielding condition, the particle size (spherical: $10-15 \mathrm{~nm}$, polygonal: 15-20 nm) was slightly small. Although it took one month or more until the particle growth was accomplished at both conditions, the grown $\mathrm{Ag}-\mathrm{An}(\mathrm{G} 1$ $\mathrm{NH}_{2}$ ) nanoparticles were stable at least for a few months.

Fabrication of silver nanoparticles was also per-
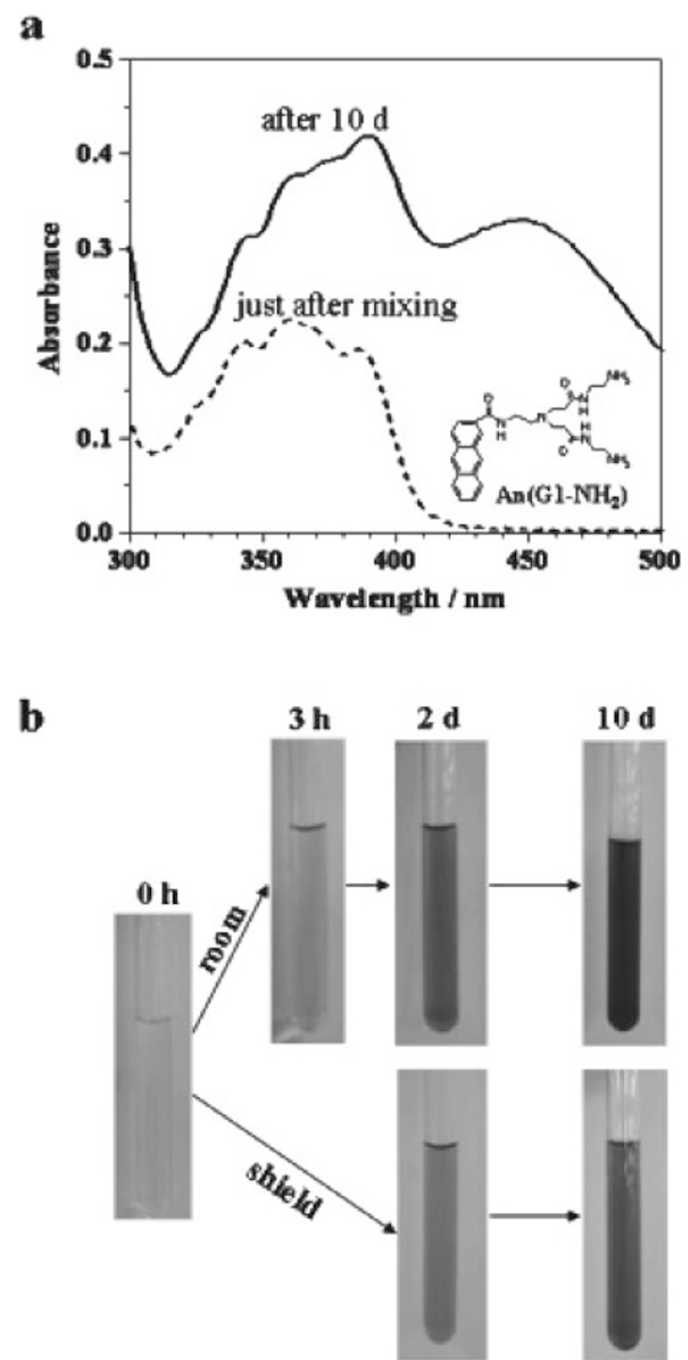

Figure 1. (a) UV-vis absorption spectra of $\mathrm{Ag}-\mathrm{An}\left(\mathrm{G} 1-\mathrm{NH}_{2}\right)$ nanoparticle suspensions (mixing ratio 1:2) under room light just after mixing and after $10 \mathrm{~d}$ (inset: chemical structure of An(G1$\left.\mathrm{NH}_{2}\right)$ ) and (b) photographs of $\mathrm{Ag}-\mathrm{An}\left(\mathrm{G} 1-\mathrm{NH}_{2}\right)$ nanoparticle suspensions (mixing ratio 1:2) under room light and light shielding conditions.
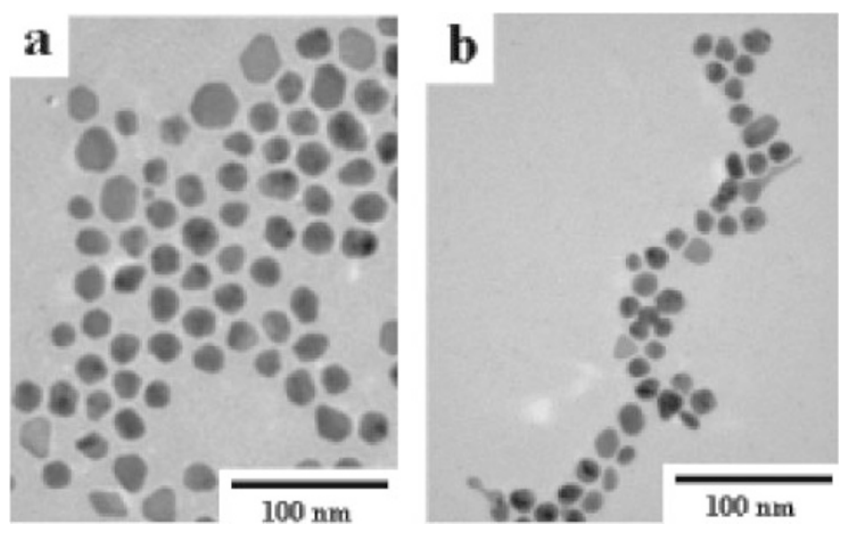

Figure 2. TEM images of $\mathrm{Ag}-\mathrm{An}\left(\mathrm{G} 1-\mathrm{NH}_{2}\right)$ nanoparticles (mixing ratio 1:2) after one month incubation under room light (a) and light shielding (b) conditions. 


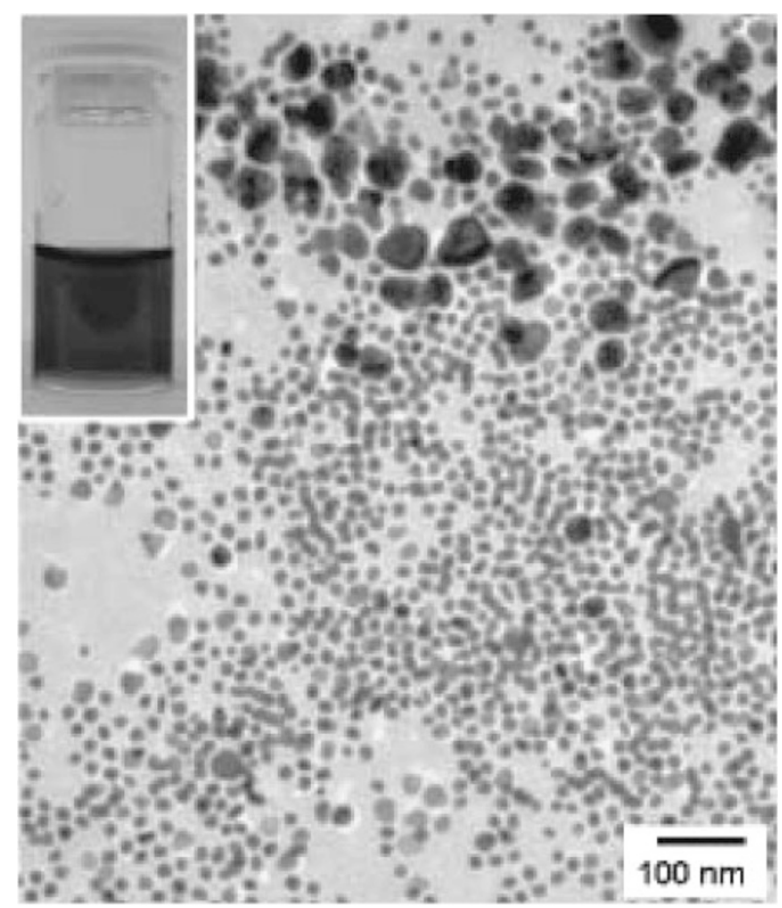

Figure 3. A TEM image of $\mathrm{Ag}-\mathrm{An}\left(\mathrm{G} 1-\mathrm{NH}_{2}\right)$ nanoparticles (mixing ratio 1:2) after $24 \mathrm{~h}$ under fluorescent lamp. Inset: a photograph of an $\mathrm{Ag}-\mathrm{An}\left(\mathrm{G} 1-\mathrm{NH}_{2}\right)$ nanoparticle suspension (mixing ratio $1: 2$ ).

formed at the condition exposed to more powerful light source than the room light, that is, at the vicinity of fluorescent lamp. In this case, the color of the suspension changed very fast: The suspension after $24 \mathrm{~h}$ was already dark brown, as seen in Figure 3 (inset), again implying the promotion of the reaction by light irradiation. Majority of nanoparticles in a TEM image of Figure 3 were spherical (size: $10-15 \mathrm{~nm}$ ) or polygonal (size: $20-35 \mathrm{~nm}$ ), but they coexisted with small quantity of irregularly shaped, large nanoparticles (size: $40-80 \mathrm{~nm}$ ). It is presumable that the irregular particles are products resulting from the fast reaction under the powerful light.

Crystal Structures of Spherical and Polygonal Ag-An(G1-NH $\mathrm{N}_{2}$ ) Nanoparticles (Mixing Ratio 1:2)

Figure 4 shows TEM images and electron diffraction patterns of $\mathrm{Ag}-\mathrm{An}\left(\mathrm{G} 1-\mathrm{NH}_{2}\right)$ nanoparticles (mixing ratio 1:2) after one month under the room light. Table I lists the observed values of Miller indices, and those are compared with the reported values (ICDD: International Centre for Diffraction Data). The spots in electron diffraction pattern of Figure 4a, which was taken for a single crystalline nanoparticle with the shape of truncated triangle, are in good agreement with the (100), (200), (300) and (110) lattice planes of a hexagonal-close-packing (hcp) single crystal. This means that $\mathrm{Ag}$ nanoparticle with its [001] direction along the electron beam is lying on the substrate. An electron diffraction pattern from a great number of silver nanoparticles, which include lots of spherical and some polygonal particles, revealed Debye-Scherrer rings, as seen in Figure $4 \mathrm{~b}$. It is indicated from the comparison with indices in literature (see Table I) that the crystal structure of main nanoparticles is a facecentered-cubic (fcc) one. It is obvious from these results that photochemically-fabricated silver nanoparticles are a mixture of spheres with an fcc structure and polygons with an hcp structure, although all previous investigations mentioned that silver nanoparticles took an fcc crystal structure. ${ }^{4,15,16}$

Some investigators have been reported that spherical silver colloids in aqueous suspensions transferred into triangular nanoplates by irradiating visible light. ${ }^{17-20}$ In these studies, they first prepared silver nanospheres by using $\mathrm{NaBH}_{4}$ as a reducer, and then irradiated visible light along the process as below;

$$
\begin{gathered}
\mathrm{Ag}^{+} \stackrel{\stackrel{\text { Stabilizer agent, } \mathrm{NaBH}_{4}}{\longrightarrow} \text { Sphere particle }}{\stackrel{h v\left(+\mathrm{Ag}^{+}\right)}{\longrightarrow} \text { triangular particle }}
\end{gathered}
$$

Furthermore, Millard et al. ${ }^{19}$ suggested that the existence of silver ions in the suspensions of spherical nanoparticles activated the photo-formation of triangular nanoparticles. In the present work, the irradiation of light may get involved in both first (particle formation) and second (structural transition) reactions and, therefore, spheres and polygons (including trigon) are concurrently produced. However, it is also likely that both spheres and polygons occur independently from sliver ions.

\section{Effects of Stabilizer and Generation on Photo-promot- ing Fabrication of Silver Nanoparticles}

Even when a commercial 4th generation PAMAM dendrimer is used instead of $\mathrm{An}\left(\mathrm{G} 1-\mathrm{NH}_{2}\right)$, photo-promoting fabrication of silver nanoparticles was possible in an aqueous solution of $\mathrm{AgNO}_{3}$ (mixing ratio 1:2) under room light, but the reaction was drastically slow: It took more than one month for getting light brown. Moreover, the suspension became turbid and generated precipitates due to the formation of inhomogeneous and large sizes of particles $(5-40 \mathrm{~nm})$ and their aggregation. Additionally, there were only spherical nanoparticles. According to these facts, terminal primary amine groups and/or branched tertiary amine groups of PAMAM dendron are concerned in the reduction of silver ions but the photo-promotion is less effective for commercial PAMAM dendrimerprotected nanoparticles than for $\mathrm{Ag}-\mathrm{An}\left(\mathrm{G} 1-\mathrm{NH}_{2}\right)$ protected nanoparticles.

The formation of silver nanoparticles under room light was progressed in the presence of anthracenylfocal PAMAM dendrons with different generations 


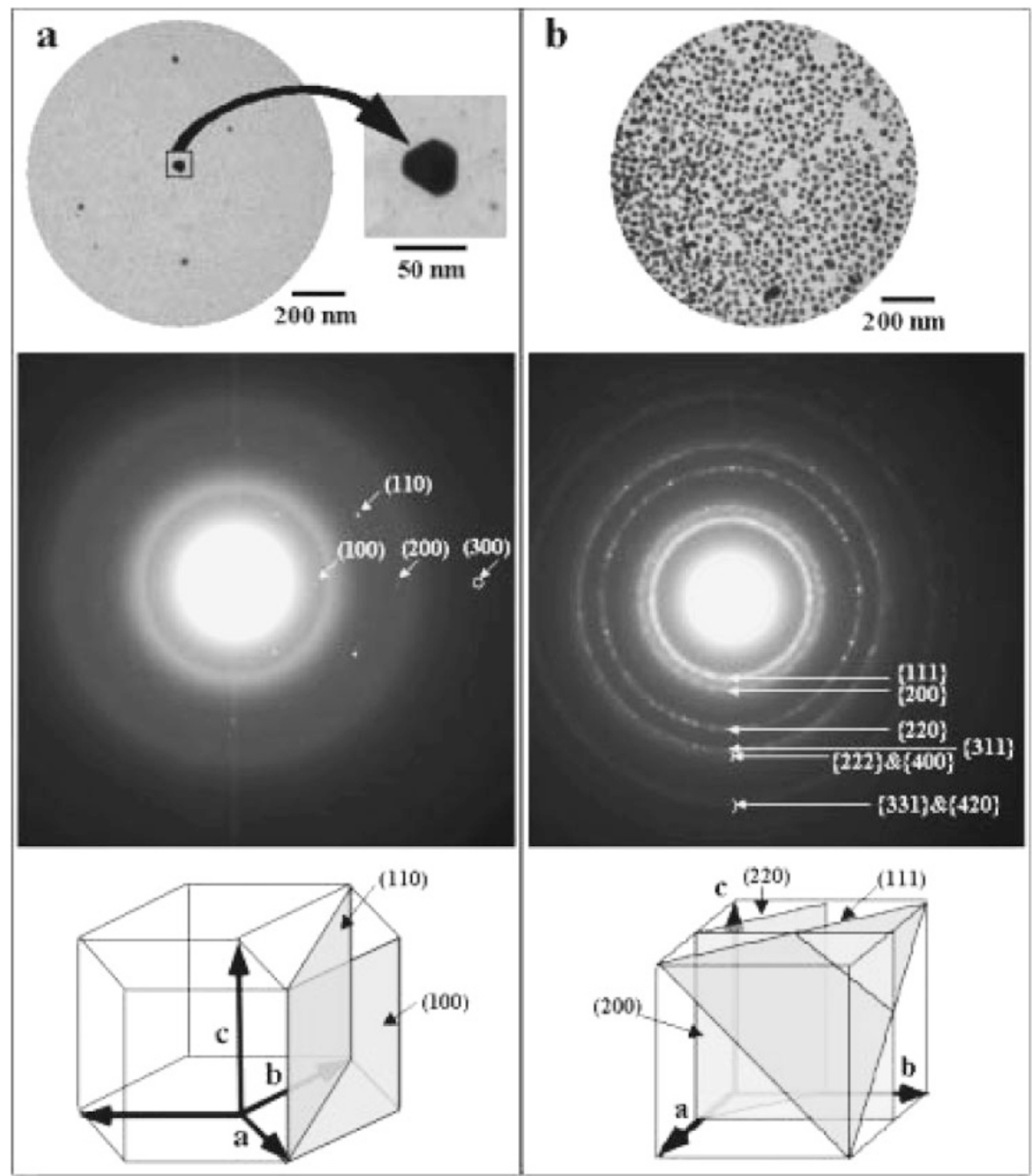

Figure 4. TEM images and electron diffraction patterns of $\mathrm{Ag}-\mathrm{An}\left(\mathrm{G} 1-\mathrm{NH}_{2}\right)$ nanoparticles (mixing ratio 1:2) after one month at room light condition and the crystal structures. (a) A single crystalline nanoparticle with truncated triangle shape; (b) A spherical nanoparticlerich mixture.

Table I. Observed electron diffraction indices for hcp and fcc structures of silver nanoparticles

\begin{tabular}{|c|c|c|c|c|c|}
\hline \multicolumn{3}{|c|}{ hcp } & \multicolumn{3}{|c|}{$\mathrm{fcc}$} \\
\hline $\mathrm{D}_{\mathrm{hkl}} / \AA^{\mathrm{a}}$ & $\mathrm{D}_{\mathrm{hkl}} / \AA^{\mathrm{b}}$ & $\{\mathrm{hkl}\}$ & $\mathrm{D}_{\mathrm{hkl}} / \AA^{\mathrm{a}}$ & $\mathrm{D}_{\mathrm{hkl}} / \AA^{\mathrm{b}}$ & $\{\mathrm{hkl}\}$ \\
\hline \multirow[t]{3}{*}{$2.47 \pm 0.03$} & 2.500 & $\{100\}$ & & & \\
\hline & & & 2.33 & 2.359 & $\{111\}$ \\
\hline & & & $2.01 \pm 0.01$ & 2.044 & $\{200\}$ \\
\hline $1.42 \pm 0.01$ & 1.433 & $\{110\}$ & $1.41 \pm 0.01$ & 1.445 & $\{220\}$ \\
\hline \multirow[t]{5}{*}{$1.22 \pm 0.01$} & 1.250 & $\{200\}$ & $1.21 \pm 0.01$ & 1.231 & $\{311\}$ \\
\hline & & & $112+002$ & 1.179 & $\{222\}$ \\
\hline & & & & 1.021 & $\{400\}$ \\
\hline & & & $089+0.01$ & 0.937 & $\{331\}$ \\
\hline & & & $0.09+0.01$ & 0.913 & $\{420\}$ \\
\hline $0.80 \pm 0.01$ & 0.833 & $\{300\}$ & & & \\
\hline
\end{tabular}

${ }^{\mathrm{a}}$ From the present paper. ${ }^{\mathrm{b}}$ From ICDD (International Centre for Diffraction Data).
$\left(\mathrm{An}\left(\mathrm{G} n-\mathrm{NH}_{2}\right), n=1,2,3\right)$ and different mixing ratios $(1: 2,1: 10$, and 1:20). Colors of suspensions at 3 and $9 \mathrm{~d}$ after preparation are compared in Figure 5. Colors thickened at lower dendron fraction and with time, and moreover the partial precipitation started in most suspensions after $9 \mathrm{~d}$, indicating faster growth and less stability of nanoparticles, as expected. ${ }^{3,5}$ Most remarkable result was that color-thickening were fast in order $\mathrm{An}\left(\mathrm{G} 2-\mathrm{NH}_{2}\right)>\mathrm{An}\left(\mathrm{G} 1-\mathrm{NH}_{2}\right)>\mathrm{An}\left(\mathrm{G} 3-\mathrm{NH}_{2}\right)>$ commercial 4th generation PAMAM dendrimer. Moreover, all $\mathrm{An}\left(\mathrm{G} n-\mathrm{NH}_{2}\right)$ generated small number of triangular and polygonal nanoparticles besides spherical ones, unlike commercial PAMAM dendrimer, as seen in Figures 2a and 6. Although the stability of nanoparticles in proportion to dendrimer generation has been reported, ${ }^{3,21}$ the present result was different from that in such reports. 


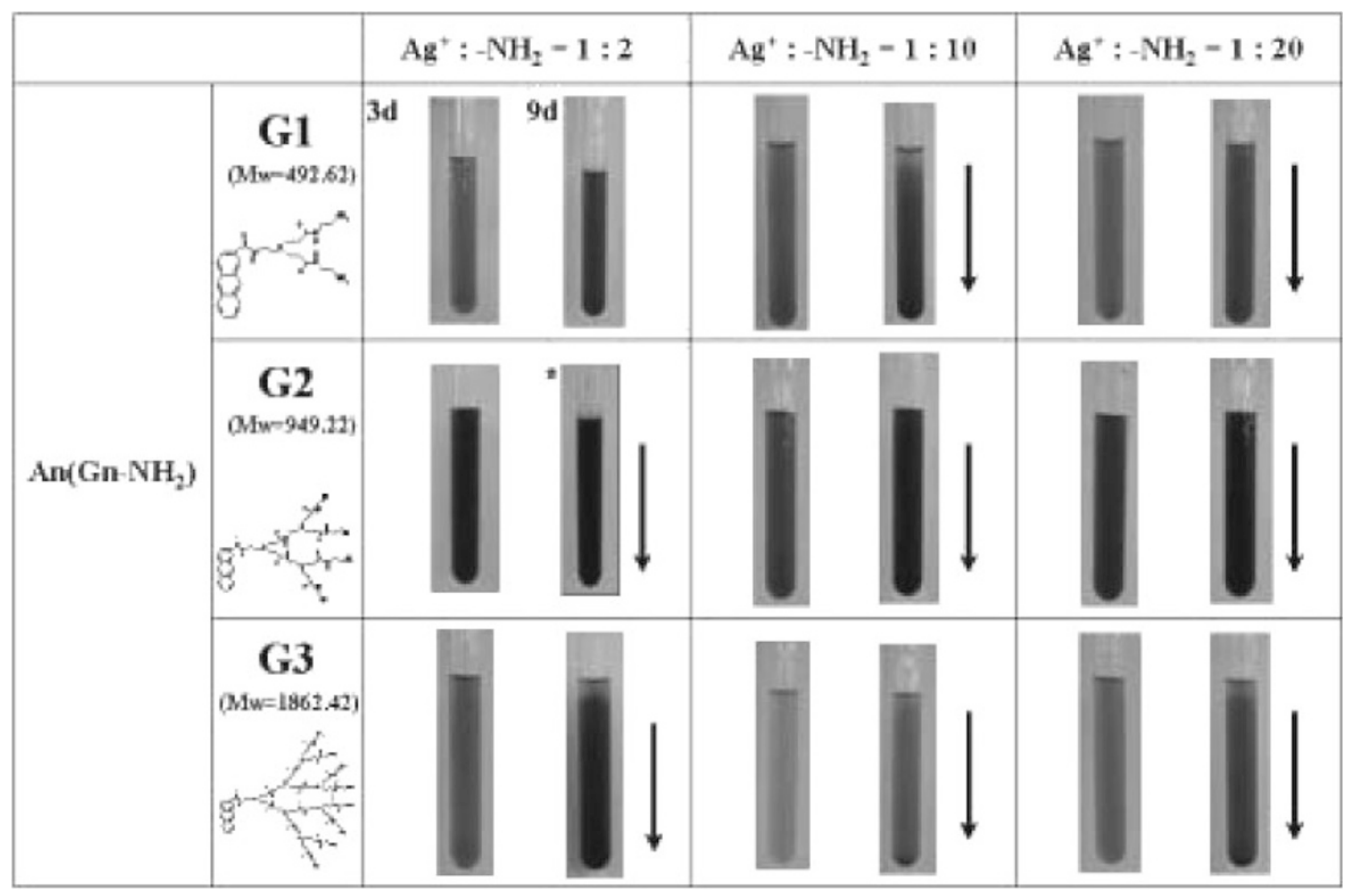

Figure 5. Photographs of $\mathrm{Ag}-\mathrm{An}\left(\mathrm{G} n-\mathrm{NH}_{2}\right)(\mathrm{G} n=1-3)$ nanoparticle suspensions at different mixing ratios and different incubation times ( 3 and $9 \mathrm{~d}$ ) under room light condition. The photograph of a suspension with $*$ symbol was taken at $14 \mathrm{~d}$. Allows indicate that the suspensions were partially precipitated.
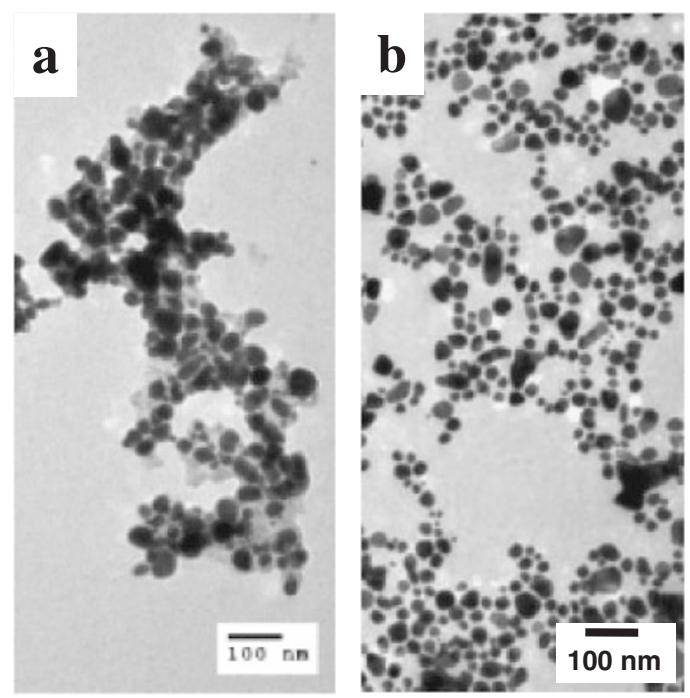

Figure 6. TEM images of $\mathrm{Ag}-\mathrm{An}\left(\mathrm{G} n-\mathrm{NH}_{2}\right)$ nanoparticles (mixing ratio 1:2) after one month incubation under room light condition. (a) G2; (b) G3.

It can be now confirmed that $\mathrm{An}\left(\mathrm{G} n-\mathrm{NH}_{2}\right)$ molecules play a key role in the photo-promoting fabrication of $\mathrm{AgNO}_{3}$, that is, the reduction of silver ions by amine groups is promoted by anthracenyl moiety, which is driven by irradiation of the light. The lone pair electrons of unprotonated amines in dendron moiety could be transferred to anthracenyl moieties by the photo-induced electron transfer (PET) mechanism. ${ }^{22,23}$ Then the electron is transferred from amine to silver ion through anthracenyl group, inducing the photo- promotion of nanoparticle fabrication.

It should be noticed that anthracene derivatives, $\mathrm{An}\left(\mathrm{G} n-\mathrm{NH}_{2}\right)$, produced polygon besides sphere. According to Millard et al. ${ }^{19}$ citrate adsorbs on the silver nanoparticle and raises the electron transfer to its surface. Then the electrons are condensed inside silver nanoparticles, enhancing the chemical reactivity on its surface. Similarly, anthracenyl moiety excited by the irradiation of light also can cause the electron transfer on the surface of silver nanoparticle. Hence, silver ions might easily be reduced on the reactive sites of nanoparticle surface, which should cause the photo-formation of polygons.

It can be supposed that the formation of silver nanoparticles is probably controlled by the generation of dendron moieties. The reaction may be fastened as increasing number of amine groups, which increases with increasing generation of the dendron. However, the efficiency of PET is reduced with increasing in size of dendron, because the efficiency depends on transfer distance. Then as the formation of nanoparticles was competed by those two factors, it was most abundant in the $\mathrm{An}\left(\mathrm{G} 2-\mathrm{NH}_{2}\right)$ solution.

\section{CONCLUSIONS}

The present work is the first report that anthracene derivatives are concerned in the photo-promoting formation of silver nanoparticles. Silver nanoparticles were fabricated by the photochemical reaction 
through $\mathrm{An}\left(\mathrm{G} n-\mathrm{NH}_{2}\right)$ as a stabilizer. The dendrons serve as takers of silver ions and act as electron-transfer agents as well. Simultaneously, the photo-fabrication of polygonal nanoparticles also occurred, and silver nanoparticles were ultimately a mixture of spherical nanoparticles with an fcc crystal structure and polygonal ones with an hep structure. Totally, the optimum condition of silver nanoparticle preparation was a reducing reaction with the aid of $\mathrm{An}(\mathrm{G} n$ $\left.\mathrm{NH}_{2}\right)$ under the room light, and $\mathrm{An}\left(\mathrm{G} 2-\mathrm{NH}_{2}\right)$ was most effective because of the competition of two effects, that is, number of amine groups in dendron as a reducer and the transfer distance in anthracenyl dendron as a PET agent.

Acknowledgment. This work was supported by a Grant-in-Aid for Scientific Research (B) (15350067) from the Ministry of Education, Culture, Sports, Science and Technology (MEXT) of the Japanese Government.

\section{REFERENCES}

1. M. Z. Zhao, L. Sun, and R. M. Crooks, J. Am. Chem. Soc., 120, 4877 (1998).

2. L. Balogh and D. A. Tomalia, J. Am. Chem. Soc., 120, 7355 (1998).

3. K. Esumi, A. Suzuki, A. Yamahira, and K. Torigoe, Langmuir, 14, 3157 (1998).

4. S. Kéki, J. Török, G. Deák, L. Daróczi, and M. Zsuga, J. Collodi Interface Sci., 229, 550 (2000).

5. A. Manna, T. Imae, K. Aoi, M. Okada, and T. Yogo, Chem. Mater., 13, 1674 (2001).

6. M. F. Ottaviani, R. Valluzzi, and L. Balogh, Macromole- cules, 35, 5105 (2002).

7. K. Hayakawa, T. Yoshimura, and K. Esumi, Langmuir, 19, 5517 (2003).

8. X. Sun, S. Dong, and E. Wang, Macromolecules, 37, 7105 (2004).

9. T. Imae, K. Funayama, Y. Nakanishi, and K. Yoshii, in "Encyclopedia of Nanoscience and Nanotechnology," H. S. Nalwa, Ed., American Scientific Publishers, 2004, p 685.

10. Y. Nakanishi and T. Imae, J. Colloid Interface Sci., 285, 158 (2005).

11. D. Wang and T. Imae, Chem. Lett., 34, 640 (2005).

12. C. Hirano, T. Imae, M. Tamura, and Y. Takaguchi, Chem. Lett., 34, 862 (2005).

13. Y. Takaguchi, T. Tajima, K. Ohta, J. Motoyoshiya, and H. Aoyama, Chem. Lett., 29, 1388 (2000).

14. Y. Takaguchi, Y. Sako, Y. Yanagimoto, S. Tsuboi, J. Motoyoshiya, H. Aoyama, T. Wakahara, and T. Akasaka, Tetrahedron Lett., 44, 5777 (2003).

15. H. W. Lu, S. H. Liu, X. L. Wang, X. F. Qian, J. Yin, and Z. K. Zhu, Mater. Chem. Phys., 81, 104 (2003).

16. S. S. Shankar, A. Rai, A. Ahmad, and M. Sastry, J. Colloid Interface Sci., 275, 496 (2004).

17. R. Jin, Y. W. Cao, C. A. Mirkin, K. L. Kelly, G. C. Schatz, and J. G. Zheng, Science, 294, 1901 (2001).

18. A. Callegari, D. Tonti, and M. Chergui, Nano Lett., 3, 1565 (2003).

19. M. Maillard, P. Huang, and L. Brus, Nano Lett., 3, 1611 (2003).

20. Y. Sun and Y. Xia, Adv. Mater., 15, 695 (2003).

21. S. Nakao, K. Torigoe, K. Kon-No, and T. Yonezawa, J. Phys. Chem. B, 106, 12097 (2002).

22. W. Wang, G. Springsteen, S. Gao, and B. Wang, Chem. Commun., 1283 (2000).

23. G. Springsteen, C. E. Ballard, S. Gao, W. Wang, and B. Wang, Bioorg. Chem., 29, 259 (2001). 